\title{
O uso de celulares, tablets e notebooks no ensino da matemática
}

\author{
The use of cellphones, tablets e notebooks in the teaching of mathematics
}

Hélio Mangueira de Almeida

heliomangueira.hm@gmail.com

\begin{abstract}
Resumo
O presente artigo tem como objetivo Identificar o desempenho e raciocínio matemático dos alunos usando aplicativos tecnológicos, apontar as ferramentas tecnológicas adequadas ao auxílio do ensino da matemática, buscando o uso de programas virtuais, celulares, tablets e notebooks, além de averiguar as dificuldades encontradas de aprendizagem. Para isso, foi realizado estudo bibliográfico sobre diversos estudiosos como Moran (2007), Demo (1993), Tajra (2001) e Paiva (2008) e uma pesquisa de campo, no Colégio Estadual Dr. Ives Orlando Lopes da Silva, com alunos do $1^{\circ}$ ano do ensino médio. Os usos de tais ferramentas podem desenvolver no aluno uma participação mais ativa e prazerosa no ambiente escolar, levando em conta que o manuseio desses aparelhos fazem o discente sentir-se mais familiarizado na escola, melhorando a qualidade do ensino-aprendizagem. Contudo, essas ferramentas exigem cuidados e acompanhamento por parte do professor, para que o manuseio das mesmas seja aplicado de forma correta e eficaz no desenvolvimento da disciplina.
\end{abstract}

Palavras-chave: Aplicativos tecnológicos; Ensino da matemática; Qualidade; Aprendizagem.

\begin{abstract}
The present article aims to identify the performance and mathematical thinking of students using technology applications, point out the technological tools appropriate to aid the teaching of mathematics, seeking the use of virtual programs, cellphones, tablets e notebooks, in addition to investigate the difficulties encountered in learning. For this, we conducted bibliographic study of many scholars as Moran (2007) Demo (1993), Tajra (2001) and Paiva (2008) and a field survey in State College Dr. Ives Orlando Lopes da Silva, with students 1st year of high school. The uses of such tools can develop in students a more active and joyful participation in the school environment, taking into account the handling of these devices make students feel more familiar in school, improving the quality of teaching and learning. However, these tools require follow-up and care on the part of the teacher, so that their handling be applied correctly and effectively in the development of the discipline.
\end{abstract}

Keywords: Technology applications; Teaching mathematics; Quality; Learning.

\section{Introdução}

O uso da tecnologia nas escolas vem crescendo a cada dia. É razoável supor que o uso da mesma de maneira correta esteja facilitando a aprendizagem dos alunos, melhorando o interesse dos mesmos pela matéria. Através da tecnologia, os discentes e também os docentes podem ampliar conhecimentos, interagir uns com os outros, trocando informações que os levem a descobrir de maneira eficaz as respostas almejadas. Diversos estudiosos como Moran (2007), Demo (1993), Tajra (2001) e Paiva (2008) têm se dedicado a pensar sobre o uso das tecnologias e a prática docente. Defendem que para o ensino se concretizar com o bom uso da internet é preciso uma mudança de paradigma. Apontam que mesmo com as mudanças ofertadas pelas tecnologias, o professor não perderá suas funções. O educador será sempre 
necessário, pois o que muda é o foco e as inúmeras possibilidades de aprendizagem, como as videoconferências, os "softwares" educacionais que proporcionam o desenvolvimento de várias habilidades, os chats, sites de pesquisa, entre outras. Com isso, deve-se também verificar o desempenho e o desenvolvimento dos discentes usando aplicativos na aprendizagem matemática, pois se trata do bom uso e aproveitamento destes, sempre monitorados pelo professor, para que, além de identificar o desempenho positivo, também possa identificar os pontos que trazem dificuldades.

Nessa proposta, constituída de ideias dos autores citados no parágrafo anterior, tornase cada vez menor a utilização do quadro-negro, do livro texto e do professor conteudista, enquanto aumenta a aplicação de novas tecnologias. Elas se caracterizam pela interatividade na aprendizagem (é uma "teia" de conhecimentos e um ensino em rede) e pela capacidade de simular situações que envolvam ambientes virtuais ligados à realidade cotidiana. Contudo, devemos sempre observar se o uso das ferramentas tecnológicas realmente está facilitando a aprendizagem matemática.

O uso das ferramentas tecnológicas em excesso e de forma errônea pode atrapalhar o desempenho dos alunos. Por exemplo, o manuseio delas para buscar resultados resolvidos pode atrapalhar o raciocínio dos discentes e consequentemente, contribuir para o fracasso da aprendizagem matemática. Por isso, é de suma importância que aplicativos e sites, entre outros, tenham um acompanhamento por parte dos docentes. Para isso, necessitam os professores estar preparados para interagir com uma geração mais atualizada e mais informada, porque os modernos meios de comunicação, liderados pela Internet, permitem o acesso instantâneo à informação e os alunos têm mais facilidade para buscar conhecimento por meio da tecnologia colocada à sua disposição.

Fazer uso de equipamentos tecnológicos, aplicativos voltados para a educação matemática e softwares educacionais, aponta para uma forma de inovação pedagógica fundamentada no construtivismo sociointeracionista que, com os recursos da informática, poderá levar o educador a experimentar uma oportunidade de compreender os processos mentais, os conceitos e as estratégias utilizadas pelo aluno e, com esse conhecimento, mediar e contribuir de maneira mais efetiva nesse processo de construção do conhecimento, como sugere Valente (1997, p.22).

Com a finalidade de analisar o desempenho dos alunos na matemática, utilizando ferramentas tecnológicas, mais precisamente celulares, tablets e notebooks, foi realizada no período de junho a meados de julho uma pesquisa de campo, no Colégio Estadual Dr. Ives 
Orlando Lopes da Silva, com alunos do $1^{\circ}$ ano do ensino médio, na qual se destacaram os seguintes itens:

- Entrevista com alunos, e como coleta de dados a utilização de questionários sobre o uso de celulares, tablets e notebooks na aprendizagem matemática.

- Conversa com professores e direção da escola sobre as dificuldades encontradas no ensino da matemática.

- Debate entre alunos e professores, mediada pela pergunta: "O uso de celulares, tablets e notebooks no ensino da matemática melhora a aprendizagem?".

O uso dos equipamentos tecnológicos, como os já mencionados, tornou-se indispensável nos dias atuais. A globalização e a necessidade de informações rápidas vêm a cada dia deixando as pessoas mais íntimas e afeiçoadas às ferramentas tecnológicas. Esse meio instantâneo de obter informação é, de fato, essencial para facilitar a busca do conhecimento. Contudo, é assunto que ainda causa desconforto para alguns professores.

\section{A utilização de celulares, "tablets" e "notebooks"}

A razão que levou à utilização de celulares, tablets e notebooks na sala de aula, surgiram das dificuldades que os alunos têm na aprendizagem matemática. $\mathrm{O}$ raciocínio e fórmulas aplicados na forma convencional trazem certo desinteresse, pois se trata de muita informação, que o aluno deve colocar no papel e consequentemente gravar na memória.

$\mathrm{O}$ enorme número de celulares, tablets e notebooks na posse de alunos me instigou a procurar saber se a adaptação do ensino da matemática a essas ferramentas traria maior interesse e melhor desempenho nos cálculos e no raciocínio lógico. Como explica Primo (1999), a interação é mútua quando implica em negociação e é reativa quando se resume ao estímulo-resposta. As 'ferramentas' que intermediam a ação do professor e o aprender do aluno são auxiliares, sempre disponíveis e muito úteis quando bem utilizadas. É a partir da criteriosa escolha das ferramentas educativas e da adequada utilização da $\mathrm{Web}$ (com todas as suas funcionalidades) que podemos almejar maneiras de trabalho mais ousadas e até mais interativas. Algumas escolas e muitos professores sugerem a proibição de celulares e tablets nas salas de aula, cuja justificativa é baseada em situações extremas, ou seja, levam em consideração os abusos por parte dos alunos que ficam conectados à internet durante as aulas, trocando mensagens inclusive em momentos de avaliação, fotografando e filmando tudo o que podem e o que não deveriam. Frequentar as aulas na posse de aparelhos eletrônicos com acesso instantâneo a informações da internet tem preocupado professores em relação à identidade dessa geração, isso por que alegam que as aulas mediadas pelos docentes estão 
ficando em segundo plano ou em plano nenhum, pois o uso de celulares no decorrer da explicação do assunto é frequente. Eles dizem que o fato que chama atenção é saber o porquê não se vê mais interesse em saber sobre as questões relevantes na escola, mas sim sobre vídeos engraçados, frases irônicas, quem está "ficando" com quem, etc.

A questão é: a proibição desses aparelhos na escola adianta? São de fato esses objetos que fazem com que os discentes percam a atenção nas aulas? Aulas desinteressantes levam o aluno a buscar algo mais atrativo, pois, segundo Içami Tiba (2006), a aula deve ser comparada a uma refeição: se a mesma estiver bem preparada e o prato estiver bem montado e bonito, agradando aos olhos, o aluno, mesmo sem estar com fome, irá querer provar. Plümer (2005) diz que essa sociedade se transforma com muita velocidade por causa dos novos meios de comunicação em tempo real e que acontecimentos em qualquer lugar do mundo são quase instantaneamente conhecidos por toda parte. A mesma reforça também a ideia de que valores, crenças, costumes e hábitos foram superados pela influência das informações sobre os comportamentos das pessoas, causando uma transformação na base das comunidades que, por sua vez, nem sempre estão preparadas para uma absorção dessa magnitude.

O que o professor deve fazer é utilizar essas ferramentas em favor de si, buscando métodos de associá-las às aulas, no caso de matemática, para que o aproveitamento e o interesse discentes sejam despertados. Em suma, a tecnologia facilita a transmissão da informação, mas o papel do professor continua sendo fundamental na escolha e correta utilização da tecnologia, dos softwares e seus aplicativos para auxiliar o aluno a resolver problemas e realizar tarefas que exijam raciocínio e reflexão.

O uso de celulares, tablets e notebooks no ensino da matemática escolar são um meio de melhorar o desempenho do discente, pois se torna um atrativo para o mesmo, envolvendoo em um mundo virtual com ferramentas capazes de estimular o interesse pela matemática.

Além disso, o uso de softwares educacionais, como aplicativos envolvendo assuntos da matemática, sites, etc., tendo um acompanhamento por parte do professor, poderá ser um meio de avaliar a maneira de ensinar e melhorar a busca pelo melhor método de ensino. Segundo José Armando Valente (1997, p.19):

\footnotetext{
Os softwares educacionais podem ser classificados em dois grandes grupos: os que promovem o ensino e os que oferecem suporte à construção do conhecimento. Os softwares que promovem o ensino são os que apresentam conteúdos prontos para os alunos, como tutorias e as enciclopédias. Já os que auxiliam na construção do conhecimento são aqueles por meio dos quais os alunos podem expressar-se, representando suas ideias e visualizando os resultados das suas ações, tais como editores gráficos, as planilhas de cálculo, os banco de dados, entre outros.
} 
No entanto, apesar de todas essas contribuições, o uso da tecnologia continua sendo um desafio, ainda há resistência por parte de alguns professores, dúvidas, dificuldades e contradições.

O professor deve estar atualizado e, conscientemente, optar por quais tecnologias utilizar nos projetos educativos, compreendendo o conhecimento cada vez mais como um processo contínuo de construção colaborativa, do qual ele é orientador. Com alunos motivados e ativos, os resultados da aprendizagem tendem a ser mais duradouros.

Philippe Perrenoud, no livro intitulado Dez Novas Competências para Ensinar, destaca a competência de utilizar novas tecnologias. Segundo Perrenoud (2000), o professor deve buscar apropriar-se das tecnologias, conhecê-las, explorá-las, conforme o seu planejamento, em situações em que propiciem ganhos pedagógicos.

\subsection{Jogos matemáticos nos celulares e tablets}

Os jogos nesses aparelhos costumam atrair crianças e adolescentes, pois estimulam a participação ativa daqueles que interagem com eles. O professor pode, então, escolher jogos matemáticos de acordo com suas propostas pedagógicas, abordando conteúdos e estratégias que pretende desenvolver, de uma forma prazerosa para os alunos.

Os jogos podem auxiliar no desenvolvimento da coordenação viso-motora, do raciocínio lógico e da construção de conceitos matemáticos. Uma boa utilização desses recursos no ensino da matemática escolar dá sentido à atividade, estabelecendo relações com os objetos de estudo e sistematizando os resultados obtidos nas atividades propostas.

Hoje, no Brasil, grande parte dos alunos possui esses aparelhos e os manuseia bem, compreendendo o funcionamento dos mesmos. A dificuldade maior fica por parte de alguns professores, que não possuem a mínima familiaridade com esses objetos, deixando de aplicar a matemática de forma a atrair o aluno para o uso adequado do aparelho. Os métodos que ainda utilizam deixam os alunos fazerem dos celulares e tablets um refúgio para se distanciarem da aula, que eles consideram chata e complicada.

\subsection{Utilização de programas de matemática no notebook}

Frequentemente, programas matemáticos são pouco usados nas salas de aula por professores, pois alguns não estão dispostos a envolver os alunos nem a si próprios nesse meio tecnológico. O fato que gera contraste é o despreparo de professores na integração de tais programas na sua prática cotidiana. No entanto, quando o professor se envolve e aplica 
esses recursos, encontra programas eficazes para que alunos usem notebooks em favor da aprendizagem matemática.

São variadas as ferramentas disponíveis para auxílio na aprendizagem dos alunos, mas encontrar professores com disposição e disponibilidade para buscar esses auxílios e estudar o uso adequado deles não é uma tarefa simples. Um dos motivos que podem ser considerados como barreira, cuja situação impede o docente a aplicar tais recursos, é a falta de incentivo para a capacitação de professores. A direção da escola e/ou órgãos competentes não disponibilizam meios e recursos para o treinamento desses profissionais da educação, tampouco oferecem condições financeiras suficientes para tal. Em alguns casos, a escola disponibiliza as ferramentas, porém não oferece o treinamento. A dificuldade ainda é maior quando se trata de professores com mais de vinte anos de carreira, cuja metodologia se limita no uso do livro didático.

Programas tecnológicos como Cinderella, Geogebra, Eureka.in e Cabri Geometre, capazes de envolver o educando e incentivá-lo a despertar o interesse pela matemática, são fascinantes, pois trazem consigo recursos que realmente facilitam o entendimento e a aprendizagem.

\subsubsection{Cinderella}

É um programa de geometria plana que permite ao aluno uma maior interatividade com a geometria dinâmica. Com esse programa o aluno pode aprender praticando, construindo e manipulando os objetos virtuais. Na utilização desse programa, a interação dos alunos com as formas geométricas melhorou bastante e o uso do "notebook" nas aulas de matemática tornou-se um aliado. Como programa destinado a fazer geometria no computador, o "Cinderella" constitui um utensílio para investigar construções geométricas de grande qualidade. O utilizador só tem de manejar o rato para interagir com o programa, que apresenta o seguinte aspecto nos primeiros momentos de utilização. Os botões apresentam imagens sugestivas, o que permite que as suas funções sejam facilmente intuídas. Para além das utilidades habituais, há botões para criar pontos, retas, circunferências, polígonos, pontos médios, perpendiculares, paralelas, para medir comprimentos, ângulos, áreas, para animar, para exportar, para criar exercícios interativos, para usar o compasso, etc. No Editor de Aspecto (no menu Propriedades) encontra-se a possibilidade de escolher as cores dos elementos (pontos, retas, fundo da construção, etc.), bem como os respectivos tamanhos, entre outras opções. A interação com uma construção torna-se muito agradável. 
A matemática em que o "Cinderella" se baseia foi, em parte, especialmente desenvolvida na sua criação. $\mathrm{O}$ esforço dos autores neste sentido foi compensado com o fato de todas as construções terem garantida total correção matemática e as animações estarem livres dos "problemas dos saltos" que afligiam outros programas similares. Ele dispõe ainda de capacidade de "reconhecer teoremas", que consiste em assinalar fenômenos geométricos não casuais, sempre que estes ocorram. Outra aplicação desta capacidade consiste no reconhecimento da correção das resoluções dos exercícios exportados de outros programas. Se um aluno construir a solução correta de um problema, o programa reconhece-o imediatamente, independentemente do método de resolução. Assim, esse programa veio auxiliar o professor na sala de aula e ao mesmo tempo incentivá-lo ao uso da tecnologia no ensino da matemática, pois quando o docente realmente busca melhorar sua mediação com os alunos, todo mundo ganha.

\subsubsection{Geogebra}

É um software de matemática dinâmica para se utilizar em ambiente de sala de aula, que reúne geometria, álgebra e cálculo. O programa permite a realização de construções geométricas com a utilização de pontos, retas, segmentos de reta, polígonos etc., assim como permite inserir funções e alterar todos esses objetos dinamicamente, após a construção estar finalizada. Equações e coordenadas também podem ser diretamente inseridas. Portanto, o "Geogebra” é capaz de lidar com variáveis para números, pontos, vetores, derivar e integrar funções, e ainda oferecer comandos para se encontrar raízes e pontos extremos de uma função. Com isto, o programa reúne as ferramentas tradicionais de geometria com outras mais adequadas à álgebra e ao cálculo. Isto tem a vantagem didática de representar, ao mesmo tempo e em um único ambiente visual, as características geométricas e algébricas de um mesmo objeto. Com ele, é possível trabalhar com geometria em três dimensões.

\subsubsection{Eureka.in}

É um software educativo considerado inovador, bilíngue, dando ao professor e ao aluno a oportunidade de entender e explanar respectivamente os conceitos de difícil interpretação matemática. Com essa ferramenta tecnológica, o estudante pode se sentir mais motivado em aprender e entender assuntos complexos de matemática, inclusive em três dimensões. $\mathrm{O}$ impacto das imagens na memória dos alunos dispensa a elucidação, além de trazer entusiasmo à aprendizagem. 


\subsubsection{Cabri Geometre}

É um software de geometria dinâmica, principalmente para a aprendizagem de geometria na escola. Ele pode animar figuras geométricas, ao contrário daqueles desenhados à mão. Está disponível para geometria plana ou geometria em três dimensões. Esse software é o ancestral de todos os demais programas de geometria dinâmica. Além disso, pesquisadores de geometria pode usá-lo para desenhar novos edifícios, difíceis de fazer no papel. É usado principalmente por professores e pode ser usado por todos que querem explorar gráficos e funções. Esse programa foi desenvolvido para os sistemas operacionais do Windows e Mac OS. O Cabri Geometre possibilita criar objetos matemáticos que podem ser manipulados dinamicamente na tela do notebook, o que não é possível quando se trabalha com lápis e papel, em que os objetos desenhados têm como característica permanecerem estáticos.

Sabe-se que a familiarização dos alunos com tais programas ainda não é frequente e contínua, pois precisam de incentivo e mediação adequada para suas utilizações. $\mathrm{O}$ importante é o docente saber envolver seus alunos nesse ambiente, onde a prática de uso de notebooks na sala de aula seja feita voltada para a aprendizagem da disciplina de matemática, orientando-os para o uso consciente das ferramentas tecnológicas na sala de aula.

O professor deve mediar tais conteúdos e usos dessas ferramentas não como detentor do conhecimento, mas como agente que está disposto a aprender juntamente com o aluno as variadas formas de melhorar sua mediação e o manuseio dos aparelhos tecnológicos. Como explica Freire (2004), o educador já não é apenas o que educa, mas o que , enquanto educa, é educado, em diálogo com o educando que, ao ser educado, também educa.

O diálogo é essencial para a produtividade na sala de aula, pois as dúvidas, os anseios e as dificuldades encontradas nesse percurso podem levar o aluno a querer desviar-se de um caminho mais apropriado para a utilização de celulares, tablets e notebooks na sala de aula.

\section{Procedimentos avaliativos com o uso de celulares, tablets e notebooks.}

Avaliar os alunos com atividades geométricas, expressões numéricas e álgebra, construídas com a utilização de aparelhos eletrônicos supracitados, outrora usados de forma aleatória pelos mesmos foi desafiador, pois tais atividades tiveram de ser bem escolhidas. Foi importante que as atividades inclú́ssem desafios questionadores, que ampliaram o conhecimento da turma. Explorar as ferramentas e levantar indagações sobre o que poderia acontecer se modificassem os dados das fórmulas, estimulou neles a curiosidade por buscar o entendimento de forma mais abrangente. 
O desempenho foi avaliado pelo desenvolvimento das ações de manuseio e entendimento das propostas matemáticas, nas quais as habilidades com os gráficos e os números eram constatadas no decorrer do uso dos equipamentos.

\section{Considerações finais}

Diante do exposto, cabe ao professor buscar as ferramentas adequadas para atrair a atenção do aluno, despertando nele a vontade de aprender e continuar aprendendo. Contudo, essas ferramentas devem ser escolhidas e exploradas corretamente.

No caso dos celulares, tablets e notebooks, que já são de posse do aluno, faz-se necessário o professor usá-los em seu favor, pois caso não busque associar a aula com esses aparelhos, ela poderá ficar monótona e sem estímulo, despertando no discente atração por atividades contrárias ao seu objetivo. O planejamento, a metodologia e o diálogo são essenciais para o sucesso da aula.

É importante que o professor tenha uma visão crítica e, sobretudo busque os melhores programas, como o "cinderella, o Geogebra e o Eureka.in, para serem aplicados na aula de matemática, pois facilitar a aprendizagem é o objetivo para quem usa a tecnologia. Dessa forma, Zabala (2002) afirma que:

\footnotetext{
As atividades de ensino devem promover aprendizagens mais significativas e funcionais possíveis, que tenham sentido e desencadeiem uma atitude favorável para realizá-las, que permitam o maior número de relações entre os distintos conteúdos, que constituam estruturas de conhecimento, por um lado. Por outro, devem facilitar a compreensão de uma realidade que nunca se apresenta compartimentada (p.186).
}

Portanto, o uso das tecnologias pode facilitar a aprendizagem e, com sua crescente utilização, os professores precisam se adequar a essa "nova forma" de aprender e ensinar, pois os programas educativos construídos para esse fim estão em um avançado crescimento.

O aproveitamento de tais ferramentas desenvolve no aluno uma participação mais ativa e prazerosa no ambiente escolar, levando em conta que o uso de tais recursos fazem o discente sentir-se mais familiarizado na escola, melhorando a qualidade do ensinoaprendizagem.

\section{REFERÊNCIAS BIBLIOGRÁFICAS}

BRITO, G. S. Purificação, I. C. Educação professor e novas tecnologias: em busca de uma conexão real. Curitiba: Protexto. 2003.

DEMO, P. Desafios modernos da educação. Petrópolis, RJ: Vozes, 1993. 
FREIRE, P. Pedagogia da Autonomia: saberes necessários à prática educativa. 29 ed. São Paulo: Paz e Terra, 2004.

GRINSPUN, M. P. S. (Org.). Educação tecnológica: desafios e perspectivas. São Paulo: Cortez, 1999.

MORAN, J. M. Novos desafios para o educador. In: A educação que desejamos: Novos desafios e como chegar lá. P. Campinas: Papirus, 2007.

PAIVA, Vera Lúcia Menezes de Oliveira. O Uso da Tecnologia no Ensino de Línguas Estrangeira: breve retrospectiva histórica. Disponível em $<$ www.veramenezes.com/techist.pdf $>$ acesso em 5 jun. 2015.

PERRENOUD, Philippe. Dez Novas Competências para Ensinar. Porto Alegre (Brasil): Artmed Editora, 2000.

PLÜMER, E. A Sociologia de Durkheim. In: TESKE, O. (Coord.). Sociologia: textos e contextos. Canoas: Ulbra, 2005.

PRIMO, Alex Fernando Teixeira. Interação Mediada por Computador. Universidade Federal do Rio Grande do Sul, 1999.

SETZER, V. W. Meios eletrônicos e educação: uma visão alternativa. São Paulo: Escrituras, 2001.

TAJRA, S. F. Informática na educação: novas ferramentas pedagógicas para o professor na atualidade. 5. ed . São Paulo: Érica. 2001.

TIBA, Içami. Ensinar aprendendo: novos paradigmas na educação. 18. ed. rev. e atual. São Paulo: Integrare, 2006.

VALENTE, J.A. O uso inteligente do computador na educação. Pátio Revista Pedagógica, Porto Alegre, ano1, n.1, p. 19-21, 1997.

VIANNA, C. R. Vidas e circunstâncias na educação matemática. São Paulo. 2000. 472 f. Tese (Doutorado) - Faculdade de Educação, Universidade de São Paulo.

ZABALA, Antoni. Enfoque globalizador e pensamento complexo: uma proposta para o currículo escolar. Porto Alegre: Artmed, 2002. 